\title{
Стратегические металлы руд и россыпей интрузий ультрабазитов Сихотэ-Алиня (Приморье)
}

\author{
Молчанов В.П. ${ }^{1}$, Андросов Д.В. ${ }^{1}$, Молчанова Н.Н.ํำ \\ ${ }^{\prime}$ Дальневосточный геологический институт ДВО РАН, Владивосток, vpmol@mail.ru \\ ${ }^{2}$ ООО «Гидрометаллург», Владивосток,631135@таil.ru
}

Аннотация. Выявлены особенности минералогии и геохимии золото-ильменитовых и золотоантимонитовых руд, связанных с Ариадненской интрузией ультрабазитов. Изучен состав основных промышленных минералов, определен комплекс попутных высокотехнологичных металлов. Полученные данные подтверждают участие этих коренных источников в формировании россыпей. Проявления титановой минерализации были поставщиками ильменита, платины, медистого и ртутистого золота, а также попутных стратегических металлов. Другим источником питания россыпей были антимонит-кварцевые жилы.

Ключевые слова: золото-ильменитовые руды, антимонит-кварцевые жилы, титаносные россыпи, ультрабазиты, Сихотэ-Алинь.

\section{Strategic metals of ores and placers of ultrabasite intrusions of Sikhote-Alin (Primorye)}

\author{
Molchanov V.P. ${ }^{1}$, Androsov D.V. ${ }^{1}$, Molchanova N.N. ${ }^{2}$ \\ ${ }^{1}$ Far East Geological Institute, Far Eastern Branch of the RAS, Vladivostok, vpmol@mail.ru \\ ${ }^{2}$ Limited Liability Company «Hydrometallurg»,Vladivostok, Russia,631135@mail.ru
}

\begin{abstract}
The features of mineralogy and geochemistry of gold-ilmenite and gold-antimonite ores associated with the Ariadne intrusion of ultrabasites are revealed. The composition of the main industrial minerals was studied, and the complex of associated high-tech metals was determined. The data obtained confirm the participation of these indigenous sources in the formation of placers. Manifestations of titanium mineralization were suppliers of ilmenite, platinum, copper and mercury gold, as well as strategic metals. Another source of power for the placers was antimonite-quartz veins.
\end{abstract}

Key words: gold-ilmenite ores, antimonite-quartz veins, titanium placers ultrabasites, Sikhote-Alin.

\section{Введение}

Национальная безопасность любого развитого современного государства в значительной мере определяется состоянием минерально-сырьевой базы стратегически важных металлов для высокотехнологичных отраслей промышленности. Так, золото не только обеспечивает финансовую безопасность государства, но и востребовано во многих отраслях народного хозяйства. В последние годы и другие металлы приобрели критическую важность для многих промышленных отраслей. Перейдя из категории экзотических металлов в стратегические ресурсы, они оказались крайне востребованными технологиями будущего (Critical..., 2014). Более 90 \% титанового сырья используется для производства белого пигмента в лакокрасочной и целлюлозно-бумажной промышленности, в производстве пластмасс, синтетического волокна, резины. Возрастает его роль в производстве катализаторов; перспективно использование нанодиоксида титана с его уникальными фотокаталитическими свойствами в солнечных батареях вместо кремниевых полупроводников. Оставшаяся часть титанового сырья идет на получение титановой губки, трансформируемой в компактный, исключительно стойкий к коррозии, легкий, высокопрочный, биосовместимый конструкционный материал, широко используемый в авиации и космонавтике, судостроении, изготовлении морских буровых платформ, спортивного инвентаря, в медицине. Уместно отметить, что редкоземельные элементы (Р3Э) играют ключевую роль практически во всех высокотехнологичных отраслях промышленности, являясь обычно незначительными по процентному содержанию, но весьма важными функциональными компонентами инновационных материалов и изделий, влияющими на современную конъюнктуру глобального рынка. Расширяющиеся сферы и нарастающие темпы потре- 
бления индивидуальных РЗЭ, их соединений и сплавов, требуют вовлечения в переработку любых сырьевых источников и промышленного производства всей номенклатуры редкоземельной продукции. Среди других металлов можно выделить ниобий, незаменимый в жаропрочных, жаростойких и нержавеющих сталях. Феррониобий в низко- и микролегированных углеродистых сталях обеспечивает высокую коррозионную стойкость, повышенную пластичность, свариваемость, прочность, увеличивает пропускную способность и снижает расходы при эксплуатации нефте-, газопроводных и обсадных труб, продлевает срок службы конструкций тяжелого, сельскохозяйственного, автомобильного машиностроения, судостроения и т.д. Легирование ниобием молибдена, титана, циркония, алюминия и меди резко улучшает свойства этих металлов, а также их сплавов. Сплавы ниобия с титаном и цирконием наиболее часто применяют для изготовления промышленных сверхпроводящих соленоидов. Металлический ниобий и его сплавы используется в основном в авиации, космической технике, радиотехнике, электронике, атомной энергетике. Многие из этих высокотехнологичных металлов (титан, цирконий, металлы платиновой группы, ниобий, тантал, гафний, ванадий, кобальт, сурьма и т.д.) присутствуют в рудах и россыпях юга Дальнего Востока, пространственно и генетически тяготеющих к интрузиям ультрабазитов Сихотэ-Алиньского орогенного пояса. К настоящему времени созрела острая необходимость их вовлечение в промышленный оборот. Решение данной проблемы должно основываться, прежде всего, на изучении минеральных форм концентрирования и особенностей распределения высокотехнологичных металлов, что и определило направленность наших исследований.

\section{Методы исследований}

Для решения поставленных задач потребовалось выполнить комплекс минералогогеохимических и технологических исследований. В пределах изученных рудо-россыпепроявлений было отобраны пробы каменного материала, которые и послужили предметами исследований. Минералогические исследования осуществлялись с применением электронно-зондового микроанализатора Jeol Superprobe JXA 8100 с системой INCA Energy 350 Oxford Instruments и электронного сканирующего микроскопа EVO-500XVP с системой INCA Energy 350 Oxford Instruments. Анализ микроэлементного состава проб был выполнен на масс-спектрометре с индуктивно связанной плазмой (ИСП-МС) Agilent 7500c (AgilentTechnologies, Япония), оборудованном распылителем Бабингтона, охлаждаемой распылительной камерой Скотта и заземленной горелкой Фассела. Использовались никелевые конусы самплера и скиммера. Определение петрогенных элементов проводилось на атомно-эмиссионном с индуктивно связанной плазмой спектрометре iCAP 6500 Duo (ИСП-АЭС) (ThermoScientific, США).

Технологические исследования были выполнены по традиционной для обогащения ильменитсодержащих песков схеме с предварительным гравитационным обогащением и последующей электромагнитной сепарацией. При этом использовались серийные концентрационные столы и электромагнитные сепараторы мокрого типа.

\section{Объект и результаты исследований}

В формировании титановых россыпей первостепенная россыпеобразующая роль принадлежит месторождениям плутоногенного происхождения, в числе которых важнейшее место занимают:

- на щитах и платформах - оруденение в анортозитовых и габбро-анортозитовых массивах, представленное рудами апатит-ильменитового состава, иногда с примесью титаномагнетита;

- в орогенных поясах: а) ильменит-магнетитовое и ильменит-титаномагнетитовое оруденение в массивах габбро-диорит-диабазовой формации; б) ильменит-титаномагнетитовое оруденение в дифференцированных габбро-норитовых массивах.

В этом ряду особое место занимают золото-ильменитовые руды и россыпи Ариадненского металлогенического пояса, связанного с базит-ультрабазитовыми плутонами, интрудирующими Самаркинский террейн юрской аккреционной призмы Сихотэ-Алинского орогенного пояса (Ханчук и др..., 2020). Этот новый для орогенных поясов тип рудоносных интрузий сформировался в обстановке раннемелового трансформного скольжения литосферных плит после прекращения юрской 
субдукции. Для базит-ультрабазитовых интрузий Ариадненского пояса характерна пластовая форма тел и субсогласное залегание с вмещающими отложениями. Поэтому, при крутонаклоненном залегании массивы в плане имеют вид сильно удлиненных в северо-восточном направлении (согласно простиранию слоев вмещающих пород) тел длиной от сотен метров до 10-15 км при ширине или мощности от 10 м до 1 км. При пологом залегании интрузивные массивы имеют близко изометричную линзовидную форму. Наряду с согласными довольно обычны и резко секущие дискордантные тела. Большинство интрузий двухфазные: первая фаза - пироксениты, дуниты, перидотиты; вторая фаза - габбро, диориты, сиениты. Металлоносные образования представлены, главным образом, пластообразными зонами (мощностью в несколько десятков и длиной в первые сотни метров) вкрапленных и массивных золото-ильменитовых руд (часто с вкраплениями минералов платиновой группы) в габбро и пироксенитах. Титан-магнетитовые и апатитовые руды редки.

Главными объектами исследований послужили руды и россыпи, связанные с Ариадненским массивом ультрабазитов, расположенном в среднем течении р. Малиновка (площадь водосбора р. Уссури, притока р. Амур). Это один из крупнейших массивов ультраосновных пород Сихотэ-Алиня. Его южная часть сложена перидотитами и оливиновыми пироксенитами, к северу преобладают ильменитовые и роговообманковые габбро, переходящие в диориты, монцодиориты и сиениты. Отличительной чертой ариадненских ультрабазитов является присутствие первичной (магматической) благороднометальной минерализации. Так, в диоритах содержания золота достигают 1.6 г/т. Высокопробные частицы золота (Au от 90.17 до 92.43 и Ag от 7.5 до 9.83 мас. \%) отмечены в ассоциации с силикатами, а низкопробные (Au от 76.52 до 80.37 и Ag от 16.91 до 23.43 мас. \%) чаще фиксируется в срастаниях с пиритом. В ультрабазитах минералы благородных металлов представлены сперилитом, золотом высокой и низкой пробы с примесью соответственно меди и ртути (до 0.5-0.8 мас. \%). Высокопробные зерна ( $\mathrm{Au}-93.53$ и $\mathrm{Ag}-6.6$ мас. \%) встречаются совместно с ильменитом, а низкопробные ( $\mathrm{Au}-50.59, \mathrm{Ag}-49.7$ и $\mathrm{Pd}-0.11$ мас. \%) - с поздними сульфидами.

С ильменитовыми габбро связано Ариадненское проявление ильменитовой минерализации (среднее течение р. Падь Тодохова). Рудные тела представляют собой залежи сложной морфологии северо-восточного простирания протяженностью до 2200 м при ширине до 400 м, и прослеженные по падению до 400 м. Среднее содержание $\mathrm{TiO}_{2}$ в них составляет $6.16 \%, \mathrm{~V}_{2} \mathrm{O}_{5}-0.086 \%$, $\mathrm{Fe}_{2} \mathrm{O}_{3}-13.28 \%, \mathrm{Sc}-0.0045 \%$. С глубиной в руде отмечается увеличение концентрации $\mathrm{Cu}$ и $\mathrm{Ni}$, достигающих, соответственно, 0.1 и $0.3 \%$. Прогнозные ресурсы $\mathrm{TiO}_{2}$ (категории $\mathrm{P}_{1}+\mathrm{P}_{2}$ ) оцениваются в размере 71 млн. т., $\mathrm{V}_{2} \mathrm{O}_{5}-944$ тыс. т, $\mathrm{Cu}-400$ тыс. т, $\mathrm{Ni}-450$ тыс. т., $\mathrm{Au}-22.5$ т и платиновые металлы - 22.5 т.

По возрастным взаимоотношениям рудных минералов и степени продуктивности в рудах выделяются две минеральные ассоциации. Главный рудный минерал ильменит, определяющий промышленную значимость объекта, пользуется наибольшей распространённостью. Его постоянным минералом - спутником является пентландит, который обычно встречается в виде изометричных либо каплевидных выделений, достигающих поперечники до 1-2 мм. Поздние сульфиды (пирротин, халькопирит, сфалерит) фиксируются гораздо реже.

К востоку от Ариадненского месторождения в верховьях р. Падь Тодохова широко развита сеть северо-восточных разрывных нарушений, контролирующих положение антимонит-кварцевых жил Тодоховского рудопроявления. Большей частью они приурочены к экзоконтакту ультрабазитов с алевролитами ариадненской свиты. По простиранию они прослежены до 4000 м, по падению - до 400 м. Авторами впервые установлена высокая золотоносность антимонит-кварцевых жил. При этом содержание основных полезных компонентов варьируется в следующих пределах: Au до 12.5 г/т, $\mathrm{Ag}-500-1820$ г/т, $\mathrm{Sb}-0.18-23.4$ мас. \%.

Главный рудный минерал - антимонит на отдельных участках занимает до 50 \% жильной массы. Состав этого сульфида $\left(\mathrm{Sb}_{2,11} \mathrm{~S}_{2,89}\right)$ от стехиометрии отличается небольшим избытком сурьмы. Самородное золото обычно наблюдается в виде мелких зерен (менее 0.25 мм) комковидных очертаний, часто в срастаниях с галенитом. Концентрации $\mathrm{Ag}$ в золотинах колеблются от 17.2 до 10.3 мас. \%, изредка отмечается небольшая примесь Rb (до 0.9 мас. \%). Минералы серебра представлены не- 
большими выделениями самородного серебра (иногда с примесью Аu до 2.5 мас. \%), аргентитом $\left(\mathrm{Ag}_{2.11} \mathrm{~S}_{0.89}\right)$ и миаргиритом $\left(\mathrm{Ag}_{1.01} \mathrm{Sb}_{1.09} \mathrm{~S}_{1.90}\right)$. Реже встречаются арсенопирит, пирит, марказит.

Ариадненский массив продуцирует ряд крупных титаноносных россыпей. Авторами обнаружено самородные золото и платина в шлихах россыпей р. Тодохова и ее правого притока руч. Потапова (Ханчук и др..., 2020). Протяженность этой аллювиальной россыпи долинного типа составляет соответственно 4.8 км при ширине до 520 м, средней мощности продуктивного пласта 7.4 м и содержанием ильменита до 375.5 кг/м³. Балансовые запасы $\mathrm{TiO}_{2}$ категории $\mathrm{C}_{1}+\mathrm{C}_{2}$ по состоянию на 01.01.2019 г. составляют 702 тыс. т, а прогнозные ресурсы достигают 500 тыс. т.

В процессе исследований шлиховые пробы прошли обогащение на гравитационной установке. Полученные концентраты посредством электромагнитной сепарации были разделены на магнитную и немагнитную фракции. Вещественный состав гравитационных концентратов характеризуется высоким выходом магнитной фракции (93-95 мас. \%) и низким - немагнитной (5-7 мас. \%). Основу магнитной фракции составляет ильменит (до 95 \%). Изредка фиксируются зерна титаномагнетита. Химический состав магнитной фракции характеризуются высокими концентрациями $\mathrm{TiO}_{2}(39.79$ мас. \%), $\mathrm{Fe}_{2} \mathrm{O}_{3}$ (34.47 мас. \%), $\mathrm{MgO}$ (1.8 мас. \%), $\mathrm{MnO}$ (0.42 мас. \%). Нельзя не отметить повышенные концентрации $\mathrm{SiO}_{2}, \mathrm{Al}_{2} \mathrm{O}_{3}, \mathrm{CaO}$, вероятно, связанных с наличием во фракции сростков ильменита с амфиболами, пироксеном и плагиоклазом. Отличительной особенностью материала магнитной фракции является высокий уровень присутствия следующих элементов (г/т): $\mathrm{V}-800, \mathrm{Nb}-210, \mathrm{Nd}-100$, $\mathrm{Co}-290, \mathrm{Cu}-490$ и $\mathrm{Zr}-280$.

Ильменит, в основном свободный, черного цвета, блеск полуметаллический, отмечается в виде кристаллов и их обломков. Кристаллы толстостолбчатые, уплощенные и изометричные, обломки угловатые и угловато-окатанные размером 0.05-2.0 мм. Грани кристаллов и поверхности обломков нередко неровные, грубоямчатые.

Состав ильменитов, по данным микрозондового анализа, характеризуется довольно значительными вариациями содержания основных компонентов (здесь и далее концентрация элементов в мас. \%) $\mathrm{Fe}-31.30-35.15 ; \mathrm{Ti}-31.09-35.15$; O - 30.02-32.82. Кроме того, в них фиксируется устойчивая примесь $\mathrm{Si}$ (до 1.20); $\mathrm{Al}$ (до 0.05); $\mathrm{Mg}$ (до 0.49); Са (до 0.16); V (до 1.10); Mn (до 1.94); $\mathrm{Hf}$ (до 1.32). В ямках и на отдельных гранях ильменитов проявляется лейкоксенизация (мас. \%): $\mathrm{Ti}$ - 30.29; $\mathrm{Fe}-6.71 ; \mathrm{Cr}-0.30 ; \mathrm{Ca}-1.07 ; \mathrm{Si}-2.37$; $\mathrm{Al}$ - 0.61; $\mathrm{Mg}$ - 1.33; O - 57.32. Исследования естественных поверхностей ильменитов выявили наличие выделений апатита $(\mathrm{P}-11.98 ; \mathrm{Ca}-0.88$; $\mathrm{O}-45.79 ; \mathrm{Al}-1.21 ; \mathrm{Si}-3.27 ; \mathrm{Fe}-1.85 ; \mathrm{Ni}-0.13 ; \mathrm{La}-8.99 ; \mathrm{Ce}-19.46 ; \mathrm{Nd}-6.42$ мас. \%), а также самородного никеля и интерметаллидов $\mathrm{Pb}-\mathrm{Sn}$.

Немагнитная фракция состоит из смеси анортита, кварца, роговой обманки, сфена и циркона. В незначительных количествах присутствуют монацит, рутил и апатит. Из рудных минералов преобладают сульфиды (единичные зерна пирита, арсенопирита, антимонита и галенита). Немагнитный концентрат характеризуется следующим химическим составом (мас. \%): $\mathrm{SiO}_{2}-49.6$; $\mathrm{CaO}$ - 13.2; $\mathrm{Al}_{2} \mathrm{O}_{3}-11.0 ; \mathrm{TiO}_{2}-9.4 ; \mathrm{ZrO}_{2}-4.23 ; \mathrm{P}_{2} \mathrm{O}_{5}-4.15 ; \mathrm{Fe}_{2} \mathrm{O}_{3}-3.23 ; \mathrm{MgO}$ - 1.84; $\mathrm{Na}_{2} \mathrm{O}$ - 1.67; $\mathrm{K}_{2} \mathrm{O}-1.18 ; \mathrm{V}_{2} \mathrm{O}_{5}-0.096$. Микроэлементы концентрата можно подразделить на две группы. Первая из них включает редкие и редкоземельные элементы (г/т): $\mathrm{Hf}-830, \mathrm{Ce}-320, \mathrm{Y}-220$. Во вторую входят благородные металлы - $\mathrm{Au}, \mathrm{Ag}$ и Pt, концентрации которых меняются в пределах 05-3.0 г/т. Самородные металлы представлены железистой платиной и серебристой, медистой, ртутистой разновидностями самородного золота. В первую наиболее представительную из них (до 70 \% всех изученных образцов) входят средне-и высокопробные разновидности золото - серебряные соединения. Эти золотины характеризуются сравнительно узким диапазоном колебаний проб от 880 до $960 \%$. Сопоставление шлихового и рудного золота, частые находки зерен антимонита, сростков арсенопирита с золотом указывают на участие золото-антимонитовой минерализации в формировании россыпи. Самородное золото ртутистого и медистого состава неоднократно отмечалось в рудо-россыпепроявлениях, тяготеющих к ультрабазитам Урала (Мурзин и др., 1987; Сазонов и др., 2002), Приамурья (Молчанов и др., 2001). В нашем случае в пользу «ультрабазитового» типа корен- 
ного источника свидетельствует также и близость макросоставов медь-ртутьсодержащих разновидностей шлихового золота и их аналогов из ультраосновных пород.

\section{Заключение}

В Приморье, одном из наиболее старых районов золотодобычи России, с участием авторов выявлены проявления золото-ильменитовой и золото-антимонитовой минерализации, связанные с Ариадненской интрузией ультрабазитов. Выполненные минералого-геохимические исследования дают основания полагать об их активном участии в формировании россыпей. Проявления титановой минерализации были поставщиками ильменита, платины, медистого и ртутистого золота, а также высокотехнологичных металлов. Другим источником питания россыпей были кварцантимонитовые жилы. Это указывает на то, что рудный потенциал региона далеко не исчерпан, но нужны новые подходы к прогнозу и поискам источников стратегического минерального сырья.

Работа выполнена при финансовой поддержке гранта РФФИ № 20-05-00525.

\section{Литература}

1. Молчанов В.П., Зимин С.С., Гвоздев В.И. Роль апогипербазитов в формировании платиноидно-золотых россыпей Гарьского узла (Среднее Приамурье) // Рудные месторождения континентальных окраин. Владивосток. Изд-во: Дальнаука. 2001. Вып. 2. Т. 2. С. 219-232.

2. Мурзин В.В., Малюгин А.А. Типоморфизм золота зоны гипергенеза (на примере Урала). Свердловск. Изд-во: УНЦ. 1987. $96 \mathrm{c.}$

3. Сазонов В.Н., Мурзин В.В., Огородников В.Н. Золотое оруденение, сопряженное с альпинотипными ультрабазитами (на примере Урала) // Литосфера. 2002. № 4. С. 63-77.

4. Ханчук А.И., Молчанов В.П., Андросов Д.В. Первые находки самородных золота и платины в ильменитовых россыпях Ариадненской интрузии базит-ультрабазитов (Приморье) // Доклады АН. 2020. Т. 492. № 2. C. 39-43. https://doi.org10.31857/S2686739720060079.

5. Critical metals handbook / edited by Gus Gunn, British Geological Survey. 2014. 455 p. 